\title{
NAS TRILHAS DA ATIVIDADE: ANÁLISE DA RELAÇÃO SAÚDE-TRABALHO DE UMA PROFESSORA DE EDUCAÇÃO FÍSICA ESCOLAR
}

\author{
IN THE TRACKS OF THE ACTIVITY: ANALYSIS OF THE HEALTH-WORK RELATION OF A \\ SCHOLASTIC PHYSICAL EDUCATION TEACHER
}

\author{
Ueberson Ribeiro Almeida ${ }^{1}$ \\ Ana Lucia Coelho Heckert ${ }^{2}$ \\ Maria Elizabeth Barros de Barros ${ }^{3}$
}

\begin{abstract}
Resumo Trata-se de um estudo sobre a análise da atividade de uma professora de Educação Física em sua primeira experiência como docente em uma escola pública polivalente da rede estadual do Espírito Santo. Busca compreender como são engendradas as estratégias no cotidiano escolar que permitiram à professora produzir saúde e escapar ao adoecimento. A metodologia adotada se construiu com as ferramentas conceituais-metodológicas formuladas pela ergologia, combinando técnicas de produção de dados, como diários, entrevistas e autoconfrontação das mesmas. A análise da atividade docente constata a incessante luta da professora em meio aos usos de si por si e aos usos de si pelos outros.
\end{abstract}

Palavras-chave atividade docente; saúde; educação física escolar.
Abstract The paper is about an analysis of the activity of a physical education teacher in her first experience as a teacher in a polyvalent public school of the state net of teaching in Espírito Santo state. It aims at understanding how engendered the strategies in the school daily life that enabled Physical Education teachers to work with health and escape from sickening are. The methodology used is constituted through the conceptual-methodological tools formulated by ergology, combining techniques of data production, like journals, interviews and their self confrontation. The teaching activity analysis finds the incessant struggle of the teachers amid the uses of themselves and the uses of themselves by others.

Keywords teaching activity; health; scholastic physical education. 
No início eu achei que era péssimo trabalhar na escola.

Depois esse péssimo foi reduzindo, não vou dizer que acho cem por cento, mas hoje eu acho que eu consegui lidar com as dificuldades que foram aparecendo. Não sei se eu consegui resolver todas elas, e às vezes nem sabia como resolver, mas tentei, e o fato de tentar pra mim já é um estímulo, uma força de não desistir no primeiro obstáculo que apareceu. Então, pra mim, deu mais força ainda pra continuar. ${ }^{4}$

No âmbito acadêmico, uma linhagem de pesquisas produzida na área da educação sinaliza o crescente adoecimento/desistência dos professores, abrangendo temas como "síndrome de burnout" (Codo, 1999), "professores reféns" (Zagury, 2006), "síndrome do esgotamento profissional em professores de EF" (Santini e Molina Neto, 2005), “abandono docente" (Fenstenseifer et al., 2006), "desinvestimento pedagógico" (Bracht et al., 2006), entre outros.

$\mathrm{Na}$ pesquisa que desenvolvemos, enveredamos por outro caminho, incidimos nossas análises nas atividades docentes, visando a focalizar as estratégias que professores utilizam para produzir saúde e lidar com as adversidades que permeiam suas práticas.

A pesquisa foi realizada com uma professora de Educação Física (EF) em uma escola pública polivalente da rede pública estadual do Espírito Santo, durante 16 meses de intenso trabalho de campo. Produzimos dados por meio de conversas informais, registros de reuniões pedagógicas, momentos de planejamento, observação de aulas, entrevistas semiestruturadas e registros no diário de campo. Todos os dados foram transcritos e enviados à professora. Depois dessa etapa, os dados se constituíram em elementos problematizadores da atividade nas sessões de autoconfrontação, 5 em que foram coanalisados pelo pesquisador e pela docente.

Do ponto de vista metodológico, trabalhamos a partir dos aportes da ergologia de linhagem francesa elaborada pelo filósofo Yves Schwartz. A abordagem ergológica traz fundamentos que constituem um conjunto de diretrizes para produção de conhecimento sobre a atividade humana no trabalho. Compreender algo da história e agir nela requer se colocar no plano do retrabalho permanente dos valores a viver.

A abordagem ergológica tem o objetivo de compreender e transformar os contextos, de colocar permanentemente em debate e em confronto: 1) as experiências de vida e de trabalho; 2) os conceitos sempre imperfeitos, sempre provisórios com relação a essas experiências, mas indispensáveis para tentar construir alguma coisa coletivamente a partir desses debates (Schwartz, 2000, 2002a, 2002b). 
A ergologia é própria às atividades humanas e, por isso, considera o trabalho em seus aspectos históricos. Trabalhar é sempre produzir 'história'. A demarcação ergológica, mesmo tendo como objetivo construir conceitos rigorosos, deve indicar nesses conceitos como e onde se situa o espaço das ressingularizações parciais, inerentes ao retrabalho das prescrições na atividade.

Antes de trazer os resultados empíricos e as análises sobre a problemática anunciada, apresentamos, sucintamente, os conceitos de atividade docente, trabalho e saúde, principais ferramentas teóricas com as quais operamos as análises na pesquisa.

\section{Atividade docente, trabalho e saúde}

Para analisar as lutas que os professores têm colocado em curso em seus processos de produção de saúde, foi necessário posicionar a lupa na atividade docente. Trabalhamos com o conceito de atividade, que, segundo Schwartz (2004a, 2007a), refere-se à esfera das microgestões inteligentes da situação, dimensão das astúcias e do tratamento das variabilidades, atividade como produção de 'histórias' dos sujeitos que buscam imprimir suas marcas no trabalho. A atividade, desse modo, não está dissociada da produção de saúde, como condição de possibilidade de gerir os riscos engendrados nos vazios de normas das prescrições, para lidar com as infidelidades dos ambientes de trabalho, com sua imprevisibilidade.

Ressaltamos, recorrendo a $\operatorname{Clot}^{6}$ (2006) e a Viera (2004), que, para a compreensão da atividade, em um sentido mais amplo do que a ação, não é suficiente focalizar apenas a realização concreta de uma tarefa e, a partir de observações restritivas, dotá-la de sentido. É necessário, antes, levar em consideração que a atividade também é constituída de seu entorno não evidente, dos atos que ficaram em suspensão, das escolhas que não puderam ser feitas, das palavras que não puderam ser ditas.

$\mathrm{Na}$ atividade, são postos em jogo recursos e competências, 7 largamente mais complexos do que aqueles explicitados na ação, do que aqueles que as prescrições solicitam. Há, desse modo, a aplicação de um capital pessoal e coletivo, pela qual Schwartz justifica a opção pelo termo "uso" - nunca só execução, mas "usos" que os trabalhadores fazem para conduzir a atividade. Durrive e Schwartz (2008) e França (2004) postulam que nisso residirá a forma indiscutível de manifestação de um sujeito industrioso 8 no trabalho.

O trabalho, do ponto de vista da atividade, é compreendido como "uso", nunca simples execução. Os que trabalham sempre colocam de "si" na atividade, sem o que o trabalho não ocorreria. Nessa esteira, ao mesmo tempo que os professores fazem "usos de si por si" para arbitrar e fazer escolhas no trabalho, há também um "uso" desse "si" que é feito pelos outros 
que compõem o ambiente escolar: os colegas, os alunos, as pessoas da comunidade, os "outros" que estão nas prescrições e ordens vindas dos órgãos do governo. Em síntese, o que acontece no trabalho é sempre o resultado da dinâmica entre os "usos de si por si e pelos outros" que atravessam a atividade. Por isso, o trabalho como uso é atravessado pelos outros. Reciprocamente, a maneira como se trabalha expressa, de algum modo, a sociedade na qual vivemos e na qual gostaríamos de viver (Schwartz, 2007b).

Daí Campos (2000, p. 235) afirmar que não é possível reduzir o trabalhador a um mero recurso, "à condição de máquina programável segundo o interesse da direção da organização". Como nos indica Schwartz (2010), isso seria impossível, uma vez que a antecipação exaustiva da atividade de trabalho não se efetiva jamais. Em contrapartida, essa situação seria, também, 'invivível' porque é nociva à saúde. A saúde começa com a tentativa de se "redesenhar parcialmente o meio em que se vive, em função de normas elaboradas por sua história" (Schwartz, 2010, p. 138). Aqui temos uma visão do trabalho humano que vai na contramão de uma certa perspectiva que o considera como mecânico, essencialmente como resultado da aplicação por uns de normas pensadas por outros.

É preciso criar um contexto para viver, o que não se faz com processos de trabalho heterodeterminados, burocratizados, fragmentados e centralizados. Os trabalhadores, quando se reúnem, podem pensar a produção de normas para seu trabalho sobre a base da experiência e de interesses partilhados. Schwartz (2010) nos convoca a considerar os sujeitos na sua habilidade essencial de produzir saberes locais investidos nas situações vividas, sujeitos capazes de criar normas que preencham as lacunas normativas dos projetos desenhados nos equipamentos sociais. Seres que, por tentarem viver em saúde, não podem jamais aceitar determinações normativas sem, ao mesmo tempo, avaliar esse uso. Viver em saúde é não se tornar puro instrumento de injunções de agir previamente pensadas pelos outros.

É na confrontação com a tecelagem das normas pré-editadas no trabalho, com o tratamento dos vazios dessas normas, uma vez que elas nunca conseguem dar conta do trabalho efetivamente realizado, que se engendra uma gestão coletiva. No entanto, esse coletivo de trabalho nunca está dado em sua composição, é variável e imensamente mais instável do que o previsto nos protocolos e organogramas dos serviços de saúde e de educação.

Fazer gestão não limitada a um local ou cargo, mas como potência inventiva do trabalhador que lida em seu cotidiano com o imprevisível dos processos laborais. A atividade humana está sempre às voltas com o real, ou seja, com o que coloca à prova as ações engendradas. Gestão como produção coletiva, que requer lugar e tempo, espaço de problematização dos acontecimentos, momento tanto de planejar quanto de avaliar as interferências produzidas nos processos de trabalho em curso. Essa concepção de gestão toma 
o cotidiano como propício para aumentar o grau de autonomia nas práticas nos locais de trabalho por meio da necessária apropriação/autoria do trabalho. A gestão, portanto, é do serviço, do trabalho, do cuidado, pautada em valores sem dimensão (Schwartz, 2010).

Assim, afirma-se a tríade atividade-trabalho-saúde que adotamos como perspectiva conceitual e postura metodológica. Partimos do conceito de saúde "vitalista" de Georges Canguilhem (1990), que tem pautado as discussões no âmbito da ergologia. Para esse autor, não é possível reduzir o conceito de saúde a um termo 'científico'. Considerando que é impossível associar normalidade e saúde, ou anomalia e patologia, o recurso às medidas estatísticas, aos valores frequentes e aos cálculos pouco nos esclarece a respeito desse conceito. Dirá Canguilhem que não é possível imaginar que a vida se desenvolva na solidão do organismo individual, nem que possamos alcançar um conhecimento dela pela comparação entre organismos. O que nos indica Canguilhem, portanto, é que a estrita conservação de si se opõe à saúde (Clot, 2010).

É por isso que o "ser vivo e o meio não podem ser chamados de normais se forem considerados em separado" (Canguilhem, 1990, p. 145), ou seja, só se pode afirmar que um ser vivo é normal quando produz o meio em que vive num processo de coengendramento, enfrentando os desafios de um meio ${ }^{9}$ sempre infiel, uma vez que é imprevisível. “O normal é poder viver em um meio em que flutuações e novos acontecimentos são possíveis" (Canguilhem, 1990, p. 146).

Para Canguilhem, a saúde não está atrelada à ausência de infortúnios, mas se produz e se conquista no movimento de criação de normas que permitem enfrentá-los. Nesse sentido, ser saudável é também desenvolver 'margem de tolerância' para lidar com as adversidades.

Pensando a saúde e a atividade docente sob esse prisma, podemos levantar algumas questões: como os docentes têm criado normas para dar conta do trabalho? Como lidam com os diversos desafios forjados nos ambientes laborais? Como fazem a gestão do trabalho? Quanto 'custa' aos docentes fazer tal gestão? Como isso interfere nos modos de conduzir a atividade e, consequentemente, na saúde do professor?

Afirmamos, então, com base no aporte teórico conceitual eleito, nossa aposta na análise da atividade docente como dispositivo de produção de saúde no trabalho, e não apenas de produção de adoecimento. Compreender como os docentes 'marcam' e produzem os ambientes de trabalho ao fazerem "usos de si" por meio da atividade é a nossa aposta ético-política. Vidas de professores que não cessam de lutar contra as nocividades, que criam modos de trabalhar com sentido de utilidade social, que produzem bem comum. O sofrimento patogênico, que pode produzir adoecimento, se efetiva quando há uma diminuição, ou tentativa de destruição, da potência de agir, de ser capaz de fazer. Sofrimento, nesse sentido, advém do impedimento ou da 
limitação para se expressar, relatar, fazer, avaliar. Ao se reduzir o raio de ação do trabalhador, corre-se o risco de anestesiá-lo.

\section{A professora Beatriz e a primeira experiência de trabalho: atividade docente e produção de saúde}

A professora Beatriz morava ao lado da escola Polivalente. Ela foi contratada por três meses com o objetivo de cumprir o último bimestre letivo de 2007, em substituição à outra docente. Recém-formada no curso de licenciatura plena pela Universidade Federal do Espírito Santo, Beatriz também estudou no Polivalente durante os sete primeiros anos do ensino fundamental, o que, segundo ela, era um importante ingrediente para a compreensão do processo de trabalho, como primeira experiência profissional, por ter vivido boas experiências de escolarização e ter estabelecido uma relação de afetividade com a escola.

Essa escola abriu as portas pra mim duas vezes. Inicialmente, quando eu entrei aqui na primeira série, eu estudava numa outra escola e, por eu ser uma menina muito chorona, a outra escola não me aceitou. Estudei aqui [no Polivavente] até a $7^{a}$ série e saí por questões de greve, essas coisas! A segunda vez, eu retornei como professora, então a escola abriu as portas pra mim mais uma vez, porque seria minha primeira experiência como professora formada. Foi minha primeira experiência, me acolheram, assim, de uma boa forma, me deram autonomia. Então essa escola representa, pra mim, um aconchego, tanto no início como agora no final. Acolheram-me em momentos totalmente distintos da minha vida. De certa forma, tenho uma relação afetiva com essa escola (Beatriz).

Retornar à escola em que estudou gerou, para a professora Beatriz, alguns riscos no que se refere a possíveis avaliações de seus pares acerca da qualidade de seu trabalho, em comparação com o bom desempenho que tinha como aluna. Nouroudine analisa a questão do risco no trabalho como defasagem existente entre as normas de segurança definidas antes das atividades e os saberes-fazereres de prudência mobilizados na atividade. Dessa forma, “a defasagem é o caldeirão da infração operante na atividade" (Nouroudine, 2004, p. 37). Assim, compreendemos que os riscos podem se constituir em desafios, em infidelidades a serem geridas pelos sujeitos que engajam o "corpo-si" no trabalho - nesse caso, reencontrar seus professores agora como pares de trabalho. Segundo a docente:

Inicialmente me trouxe um pouco de medo, pois, apesar de chorona, eu era boa aluna, então foi uma cobrança de mim pra mim mesmo. Eu fui uma boa aluna e aí, 
como professora, eles esperavam algo de mim, talvez não intencionalmente. Então, foi interessante, foi engraçado os professores terem dado aula pra mim na $5^{\mathrm{a}}$ e $7^{\mathrm{a}}$ séries e agora voltar e reencontrar. Por outro lado, acabou me trazendo um pouco de medo, insegurança, pela questão de às vezes surgirem comparações mesmo: 'Ah, era boa aluna e agora?'. Aí não sei, mas foi bom pro meu trabalho (Beatriz).

É a partir da análise efetuada por Canguilhem que Nouroudine (2004) afirma que o homem dito 'são' (saudável) não o é a priori, ou apenas se pode autointitular aparentemente saudável. A saúde é um equilíbrio que ele alcança mediante rupturas incoativas. Por isso, a ameaça da doença torna-se um constitutivo de saúde, um risco necessário, algo a ser gerido, um operador de saúde no trabalho.

Diferentemente dos professores que moravam em comunidades distintas da escola onde trabalhavam, a professora Beatriz se deparava, a todo instante, com pessoas que, de algum modo, podiam tornar seu trabalho visível, o que, ambivalentemente, gerava "insegurança" de ser mal avaliada (e as repercussões disso na comunidade, na roda de amigos, na família, na vizinhança) e "segurança" de poder contar com o apoio e com o acolhimento de pares que se construíram bem antes da 'história' do trabalho docente. Logo que chegou à escola, a professora avaliou:

Eu conhecia grande parte dos alunos. Cada turma que eu entrava e falava: 'Minha nossa! Moro aqui, participo da Igreja Católica'. Então, há um monte de alunos daqui que já me conheciam da igreja, já tinham me visto. Tem alunos daqui que eu conheço. Moramos perto, somos vizinhos. Isso me trouxe certa insegurança, ao mesmo tempo em que poderia me proporcionar segurança: 'Ah... já conheço alguém!'. Paradoxalmente, isso me trouxe insegurança também, porque aquelas pessoas já faziam parte do meu ambiente social (Beatriz).

Não apenas os alunos, mas "os pais me conheciam, eu não chegava a ser amiga do ponto de vista íntimo, mas conhecia os pais e conhecia os filhos". Se, no ambiente de trabalho da professora, produziram-se inseguranças relativas às avaliações dos outros que eram da mesma comunidade, isso não significou uma ameaça que impedisse que o trabalho fosse bem desenvolvido. Ao contrário, a sensação de estar sendo "avaliada por todos os lados, de certa forma ajudou, pesou positivamente, foi algo a mais!" (Beatriz). Clot (2006) lembra que eficiência no trabalho não significa apenas realizar as tarefas técnicas, mas se atrela também a poder se apresentar ao outro como expressão de aceitação e de maneira amigável, condição de possibilidade para composições de boas relações no ambiente de trabalho. O trabalho é sempre dirigido a alguém. Apesar de evidentemente pessoal, não é privado, é necessário entendê-lo como vinculado a um grupo específico de 
trabalhadores, uma vez que o trabalhador está vinculado a um coletivo que vem tecendo seu ofício ao longo das histórias que constrói.

Eu acho gratificante! São essas coisas que estimulam, que ajudam! Esses dias, eu estava passando na rua, um aluno me viu e disse assim: 'Oi, professora!'. Eu disse: 'Olá, tudo bem!' [sorridente e com um brilho no olhar]. Eu achei curioso que com ele há uma identificação, um feeling. Eu passava nos corredores lá da escola, ele sempre perguntava: 'Professora, você vai dar aula hoje?'. Aí você percebe que alguém deu alguma importância para aquilo que você estava fazendo no trabalho! (Beatriz).

A combinação da primeira experiência com o fato de trabalhar num ambiente 'familiar', participar e morar na comunidade e ter construído uma relação afetiva com a escola, quando aluna, constituiu-se num potente motor que contribuiu para a professora Beatriz mobilizar conhecimentos e fazer usos diversos para continuar no trabalho. Também foi importante para o desenvolvimento de margem de tolerância diante de uma experiência inicial que se mostrou fortemente adversa.

Solteira e com 24 anos, Beatriz viveu sua primeira experiência como professora de EF, lecionando para sete turmas do primeiro e cinco turmas do segundo ano do ensino médio. Essa empreitada representou um grande desafio, uma vez que a docente teve exíguas vivências em sua formação inicial universitária com esse público escolar, como ela mesma declarou:

No início, eu senti uma diferença muito grande. Tive contato com a Criarte, que era com educação infantil, com crianças de quatro anos. Quando eu fiz estágio curricular, fiz com crianças de $4^{\mathrm{a}}$ série e $5^{\mathrm{a}}$ série! Então, assim, nunca tinha lidado com adolescentes dessa faixa etária de 15 anos, e daí pra cima (Beatriz).

Para Hubermam (1999), na tensão das primeiras experiências com a realidade de seus meios de trabalho é que os professores se confrontam com processos de formação profissional e sentem os impactos de suas escolhas, tanto no que diz respeito a opções acadêmicas quanto às que os constituem como professores e, portanto, fazendo parte de um coletivo ou categoria profissional que tem uma história que é transpessoal. Buscando suprir as insuficiências da formação inicial e marcar seu lugar no chão da escola, a professora Beatriz mobilizava táticas, reorganizava o tempo, jogava com as brechas de normas para se manter e garantir qualidade no trabalho, o que pode ser evidenciado na maneira como ela fazia o planejamento das aulas.

Mesmo que eu não tivesse fazendo alguma coisa, eu estava pensando no que eu poderia fazer, então, mesmo fora da escola, eu sempre estava pensando: ‘Como eu 
vou fazer isso? Como eu vou fazer isso?'. Por exemplo, quando eu entrei: 'Como eu vou trabalhar? O que eu vou trabalhar?'. Eu chegava aqui, fazia o que eu tinha planejado. Nem sempre dava certo, mas tentava fazer, e do momento que batia o sinal da última aula, que era $11 \mathrm{~h} 30 \mathrm{~min}$, era a tarde e parte da noite pensando, procurando alguma coisa, pensando e procurando alguma coisa que pudesse acrescentar, até porque eu não sabia o que fazer mesmo! Completamente perdida, era praticamente o dia inteiro pensando na escola. Estava na aula de inglês, mas minha cabeça estava assim: 'Meu Deus, ainda não consegui projetar o que eu vou trabalhar, o que eu vou fazer'. Então, assim, em todas as horas, mesmo que não fossem concretas ali, de estar fazendo, o pensamento estava tentando achar uma solução para o que eu tinha que fazer. Então, assim, era praticamente 24 horas. Perdia o sono também, às vezes pegava parte da noite ou então acordava muito mais cedo do que eu tinha que acordar pra vir trabalhar pensando nisso. Então ocupava meu tempo praticamente inteiro. Depois de certo tempo, isso já foi ficando mais tranquilo. Assim, ocupava 24 horas, mas passou a ir ocupando a parte da tarde, porque aí eu já conseguia me organizar de forma melhor, eu já conseguia dormir de forma melhor, não cem por cento, mas isso foi melhorando com o tempo (Beatriz).

Os primeiros dias não foram fáceis para a professora Beatriz, porque ela chegou e, imediatamente, tentou romper com a cultura da EF cristalizada nos alunos e com a maneira de trabalhar da professora anterior. Sentindo-se culpada e incapaz de envolver os alunos do ensino médio em suas aulas, Beatriz experimentou, por algumas vezes, aquilo que Brito, Athayde e Neves (1998) designam de "transtornos mentais leves". Quando chegava sexta-feira, ela "dava graças a Deus".

No domingo, eu já estava sofrendo porque estava perto da segunda. Eu me sentia bem na sexta, sexta à tarde eu estava feliz da vida, sábado eu já começava a ficar angustiada, porque eu sofro por antecipação. Sábado à noite já começava a sofrer porque estava perto da segunda-feira: 'Minha Nossa Senhora!'. Quando eu lembrava que tinha que vir para escola, domingo à noite eu tinha crise de choro, segunda de manhã, antes de vir pra escola, direto, mamãe falava: 'Você não vai para escola'. Eu dizia: 'Eu vou, eu tenho que ir trabalhar'. Saía de casa chorando, com o olho cheio de lágrimas, chegava aqui na escola, respirava fundo... 'É meu trabalho, eu preciso suportar' (Beatriz).

Muito preocupada com a imagem negativa que os outros pudessem construir a seu respeito, a professora tentou resolver os problemas de ansiedade e perda de sono consultando um médico psiquiatra, o que agravou seu estado emocional, gerando sentimento de inutilidade e desqualificação no trabalho. Segundo a docente, 
Ele [o médico psiquiatra] falou como eu deveria agir com os alunos, como eu deveria dar aula, que aí eu não me frustraria! Por exemplo, foi o que ele falou: ‘Olha, deixe-os [os alunos] fazer o que eles quiserem fazer, não é mais fácil? EF [Educação Física] é um momento de lazer pra eles, porque eles ficam mais presos na sala de aula'. Mas, justamente, essa prescrição só aumentou meu sofrimento! (Beatriz).

Recorrendo a Canguilhem (1990), é possível dizer que o médico psiquiatra desconsiderou a implicação da professora Beatriz na constituição do ambiente de trabalho, bem como aquilo que tem valor para sua saúde: a potencialização de seu processo de trabalho. A saúde não está a cargo exclusivo da medicina ou de qualquer ciência que se julgue da 'saúde'. Os trabalhadores e, nesse caso, os professores, são autorizados a dizer acerca daquilo que é saudável e que os fazem sofrer, uma vez que a mesma dor pode afetar os sujeitos de maneiras distintas e solicitar enfrentamentos singulares.

Sentimento de inutilidade e poder de agir reduzido podem levar o trabalhador a construir sobre si mesmo uma imagem que se apresenta na situação de trabalho diretamente relacionada com uma desvalorização do que faz e o consequente aprisionamento no sofrimento. Nessa perigosa trama, todos os acontecimentos passavam a ser superdimensionados e ganhvam conotação negativa por parte da professora:

Sentia-me muito angustiada, muito inquieta, apreensiva nos momentos difíceis, angustiada. Às vezes parecia que as coisas só aconteciam comigo, de sentir que eu não era capaz de fazer, capaz de realizar algo. Incapacidade. Parecia que tudo era muito mais forte que eu. Eu via que uma coisa que não era tão grande, eu via de forma muito maior pro lado negativo. Então aquilo me abafava de certa forma. Mas aí, no meio desses momentos difíceis, tinha também os momentos de alegrias, às vezes é até engraçado. E, quando um aluno me chamava de professora na rua, isso, às vezes, me trazia algo de bom e às vezes eu pensava: 'Meu Deus, onde eu passo tem alunos, todo lugar que vou tem alguém me cumprimentando: 'Ei, professora!'. É engraçado, é legal! Não sei se era reconhecimento, eu sentia que os alunos, apesar de eu achar que o trabalho não estava tão bom, eu sentia nisso acolhimento (Beatriz).

Todo início de trabalho na escola, seja a primeira experiência ou não, solicitará dos professores margem de tolerância em respeitar "um tempo pedagogicamente necessário" para a construção de relações de confiança com o alunado, sem o qual a tentativa de ensino de conteúdos tende a sucumbir. É fundamental dar-se tempo para 'ler' o cotidiano e estabelecer parcerias com os colegas de trabalho. 
Eu pensei que fosse conseguir mudar muitas coisas, mas vi que eu não consigo mudar isso com um curto espaço de tempo, que eu preciso de um tempo maior! Como foi minha primeira experiência, não que eu esteja segura, mas, de certa forma, um pouco mais confiante. Ao mesmo tempo em que eu sei que não é possível modificar num curto espaço de tempo, eu percebi que é possível fazer alguma coisa. É possível tentar fazer algo, e que a culpa não é só minha, envolve outras questões (Beatriz).

Para Pérez Goméz (1998), competência docente não é algo que se pode determinar do exterior. Cada professor desenvolve competências de acordo com as possibilidades que podem ser criadas na relação com o meio de trabalho. Contudo, algumas competências relacionais, como desenvolver a compreensão situacional, habilidades de argumentar, de negociar e mediar momentos de tensões e conflitos são tão importantes para a vida no trabalho escolar como o domínio de conteúdos e técnicas didáticas. Foi o que teve de aprender no trabalho a professora Beatriz. Desde que chegou à escola, ela não se satisfazia em ensinar apenas os esportes tradicionais para os alunos: futebol, voleibol, basquetebol e handebol. Ela acreditava que, por meio desses esportes vivenciados sob a lógica exclusiva da competição, estava contribuindo apenas para fortalecer valores do sistema capitalista e da reprodução cultural. Portanto, para propor e implementar mudanças didático-pedagógicas, ela afirmou que teve de aprender no trabalho e por meio da atividade a "negociar" com os alunos. Mas até o negociar com os discentes guarda riscos: os de se conformar em apenas atender as vontades e interesses dos alunos.

A professora Beatriz passou a modificar sua atividade a partir do momento em que a percebeu como dispositivo importante na gestão do trabalho. Isso foi evidenciado quando ela estabeleceu uma negociação com os alunos a fim de iniciar o ensino do conteúdo atletismo. A professora relatou que entrou na sala de aula para fazer a proposta de ensino-aprendizagem para uma das turmas na qual os alunos estavam resistentes a qualquer conteúdo diferente do que eles já conheciam. Segundo ela, a conversa/negociação se desdobrou da seguinte forma:

- Bom dia! [para um aluno que está na porta da sala] (professora Beatriz).

- Lá vem, né, professora? Já vem você! (aluno Lico).

- Como eu tinha dito na outra aula... [interrupção] (professora Beatriz).

- Professora, a gente já falou que não vai fazer isso não, não vamos fazer atletismo!

A gente não vai fazer, não vai! (aluno Fábio).

- Pois é, como eu falei na outra aula... (professora Beatriz). 
Os alunos interromperam novamente,

- Professora, a senhora não vai vir com esse lance de atletismo, não, né? (aluno Lico).

- Calma, gente, vocês nem esperam eu falar. Vocês sabem o que eu vou falar? (professora Beatriz).

- Fala aí, professora! (aluno Tom).

- A gente tinha combinado de trabalhar o atletismo, só que a gente vai começar a trabalhar o atletismo na próxima aula. Esta aula vai ficar livre pra vocês, vocês vão jogar o que vocês quiserem - eu estava com tudo preparado para iniciar o atletismo naquele dia - com uma condição: na próxima aula, nós vamos começar o atletismo (professora Beatriz).

- Está bom, professora, na próxima aula, vamos começar o atletismo (aluno Lico). Daí pra frente, tranquilo, aí eu voltei na sala na próxima e aula disse: ‘Hoje vamos começar o atletismo'. Houve algum embate, mas, para eu conseguir dar o que estava me propondo a fazer, eu tinha que fazer algumas negociações, soltar a corda e puxar um pouco a corda (professora Beatriz).

Apesar de ter sido uma aluna que poucas vezes estudou atletismo nas aulas de EF no processo de escolarização, e por ter optado não cursar essa disciplina na universidade, a professora Beatriz mobilizou esforços para tentar ensinar algo 'novo' para seus alunos, ainda que não dominasse, tecnicamente, o conteúdo. Nesse sentido, constatamos que as estratégias e astúcias produzidas na gestão da atividade docente compõem um processo formativo indissociável da luta por saúde no trabalho. É o que nos mostrou a docente:

Busquei materiais para as aulas, conversei com professores que já tinham experiência em dar aula de EF, tanto com professores da universidade como professores da escola mesmo. Sentava, lia, procurava na Internet coisas que poderiam me ajudar. Não tinha a mínima noção do que dar, do que passar para eles, aí tentava buscar materiais, livros, Internet, trocas de experiências com outros professores. Isso acabou me ajudando um pouco porque eu vi que os problemas que eu estava enfrentando não eram só meus (Beatriz).

De acordo com Wittizorecki e Molina Neto (2005), os dilemas e as adversidades com os quais os docentes se confrontam cotidianamente nas escolas, as particularidades das situações concretas de cada contexto social no qual estão imersos, as contingências relativas ao ato educativo e a complexidade que delineia o processo de trabalho docente constituem a base necessária para que esses trabalhadores maquinem diariamente uma série de engenhosidades (como a construção da relação de cooperação e aliança) e saberes (como a capacidade de leitura da realidade, a tolerância às adversidades), para lidar não só com as demandas e necessidades que essas condições lhes 
colocam, como também com suas próprias incertezas e desafios. Nesse sentido, criar formas de ensinar o conteúdo atletismo, ressignificando-o no âmbito de um projeto educativo cooperativo-solidário, foi o desafio e a escolha da professora Beatriz, que pensou e efetivou o ensino desse conteúdo:

Na corrida, havia duas equipes. A gente marcou as raias para que, nessa corrida, nós pudéssemos aferir o tempo, mas o tempo não seria de um aluno só, não um tempo individual, mas o tempo da equipe. Essa era a proposta inicial. Nas corridas, um fez em um minuto, outros fizeram em 50 segundos, o outro fez em 30, o outro fez em 10. Somaria e esse seria o tempo da equipe, então seria um trabalho colaborativo. Tinha pensado em fazer assim. No arremesso de peso a mesma coisa, era a soma de tudo, não estaria incluído aí o melhor ou o pior, mas que eles se percebessem como um conjunto, mas não deu certo, porque a participação dos alunos foi pequena (Beatriz).

O fato de a aula não ter repercutido como o esperado não mais provocava na professora Beatriz sentimento de incapacidade, indignidade e desqualificação, mas a certeza de que era necessário tentar outra via. A considerada "pequena participação" se restringiu apenas à maioria dos meninos que não aceitavam aprender um conteúdo diferente do futebol. Se a aula de atletismo não mobilizou esses alunos no primeiro momento, as meninas e parte dos meninos que eram excluídos do jogo de futebol durante as aulas foram contemplados pela produção de estratégias que a professora implementou quando diversificou os conteúdos e as formas de ensiná-los. Com o objetivo de incluir todos na aula, a professora modificou o planejamento e nos apresentou o que considerou como aula bem-sucedida:

Trabalhei um jogo de trilhas, uma espécie de caça ao tesouro. Nesse deu certo! Nesse eu consegui trabalhar em equipe, eles montaram pistas, onde reconheceram o espaço da escola. Aí eles fariam perguntas relacionadas aos esportes. Nessas perguntas relacionadas aos esportes, eu não restringi só ao atletismo, eram cinco pistas, a primeira eles falaram, e as outras quatro eles esconderam. Nessa, o trabalho de equipe deu certo. Eles realmente trabalharam em equipe, todos pensando juntos na hora de esconder as pistas. Na maioria das turmas, saía o grupo inteiro para o pátio, aí, quando demorava muito pra achar a pista, eles davam dicas (Beatriz).

A professora falou com satisfação acerca da aula que considerou ter sido exitosa e afirmou que o mais importante foi que

(...) os alunos que estruturaram buscaram informações que eles não sabiam sobre o esporte. Eles buscaram, me procuraram para poderem elaborar as pistas. Aí tinha o tempo da equipe. Eles liam a primeira pista e a primeira pergunta, 
eles tinham tempo de responder. A partir daí, eu começava a marcar o tempo, aí eles tinham que trabalhar juntos! Foi muito interessante, eu me diverti muito, muito, nesse processo, muito interessante! (Beatriz).

Viver saúde no trabalho e em outras esferas da vida será sempre tentar gerir os encontros em que eclodem as infidelidades e histórias. Os trabalhadores se apropriam das normas, transgridem, jogam com elas inventado novas normas, isto é, renormalizam permanentemente por meio da atividade. Isso significa que há vida, significa a possibilidade de não se deixar dominar inteiramente pelos organogramas prescritos nas escolas. Afirmar uma situação de trabalho como uma história "é nos conduzir a tocar o dedo no que o trabalho nos engaja e nos custa, porque ele nos obriga sempre mais ou menos a criar, a inventar e, por aí mesmo, a nos (re)inventar" (Schwartz, 2005 , p. 4). Nessa esteira, fazemos as escolhas de vida que nos orientam a desenvolver mais ou menos engenhosidade, inventividade, permitindo que recombinemos de tal ou tal maneira, em tal ou tal direção nossas experiências e saberes acumulados em nossa história.

\section{Considerações finais}

A constante luta e movimentos empreendidos pelos sujeitos na produção de saúde no trabalho são emblemas que não podem ser escamoteados ou tornados invisíveis. É imprescindível dar visibilidade à produção de saúde e àquilo que causa sofrimento aos professores em seus ambientes de trabalho. Saúde, portanto, não é um conceito alheio aos sujeitos; os docentes estão autorizados a dizer e a refletir a respeito daquilo que potencializa a atividade e que produz sofrimento patogênico ou paralisante e adoecimento no trabalho.

O ambiente de trabalho da professora Beatriz não se restringiu à escola, mas transbordou pelas ruas da comunidade, igreja, supermercados, feiras, praças e por todos os cantos da comunidade. Se riscos sui generis se apresentaram na combinação dos elementos que permearam a sua 'história' de trabalho no Polivalente, a gestão desses riscos se constituiu nas alavancas que lhe permitiram criar, renormalizar e tornar possível o investimento na atividade docente. Logo, a situação de trabalho que se apresentava em forma de dor-desprazer-sofrimento10 sofreu uma torção no sentido da produção de uma relação de prazer-saúde. 11

Dar visibilidade às movimentações cotidianas que emergem nos processos de trabalho docente traz como efeito outros valores às experiências que se constituem nesse processo, valores de bem comum, não dimensionáveis, bem como a qualificação desses movimentos como importantes formas de 
indagar e desmontar os modos de gestão do trabalho e certos tipos de políticas instituídas que buscam estigmatizar e amputar o poder dos professores de "usar de si", a sua potência de criação.

Acentuar a inoperância e a passividade dos professores diante das adversidades e problemas do ambiente de trabalho tem servido para enaltecer e eleger alguns grupos sociais, e até mesmo o próprio Estado, como protagonistas exclusivos das transformações históricas.

Acompanhando o pensamento de Barros de Barros e Heckert (2006), partimos, também, da premissa de que a situação de nocividade das escolas não pode se limitar à apresentação de uma espécie de 'síndrome de desistência' ou 'síndrome do esgotamento profissional', que pode ser caracterizada pela exaustão emocional e pela falta de compromisso com o trabalho. Indicar esse processo de desistência dos docentes é importante; não se trata de negá-lo. Entretanto, torna-se importante também dar visibilidade às ações que apontam a teimosia e a insistência dos professores em transformar positivamente as condições de trabalho na escola, as movimentações cotidianas e suas lutas por saúde.

\section{Nota do Editor}

Este artigo é resultado da dissertação de mestrado do primeiro autor, intitulada Nas trilhas da atividade docente: análise da relação saúde-trabalho de professores de Educação Física no cotidiano escolar, apresentada em 21 de maio de 2008, na Universidade Federal do Espírito Santo. A segunda e a terceira autoras participaram na condição de co-orientadoras do estudo e colaboraram com a produção deste artigo, que foi financiado pela Fundação de Apoio à Ciência e Tecnologia (Facitec), do município de Vitória, Espírito Santo. 


\section{Notas}

1 Membro do Laboratório de Estudos em Educação Física, do Centro de Educação Física e Desportos, da Universidade Federal do Espírito Santo (Lesef/CEFD/Ufes), e do Núcleo de Estudos e Pesquisas em Subjetividade e Política, do Centro de Ciências Humanas e Naturais (Nepesp/CCHN), da Ufes, Espírito Santo, Brasil. Mestre em Educação Física pela Ufes. <uebersonribeiro@terra.com.br>

Correspondência: Rua Clarício Alves Ribeiro, n. 22, Oriente, CEP 29150-670, Cariacica, Espírito Santo, Brasil.

2 Professora do Departamento de Psicologia e do Programa de Pós-Graduação em Psicologia Institucional da Universidade Federal do Espírito Santo (Ufes), membro do Núcleo de Estudos e Pesquisas em Subjetividade e Política, do Centro de Ciências Humanas e Naturais (Nepesp/CCHN), da Ufes, Espírito Santo, Brasil. Doutora em Educação Brasileira pela Universidade Federal Fluminense (UFF). < anaheckert@uol.com.br>

3 Professora do Departamento de Psicologia e dos Programas de Pós-Graduação em Educação e em Psicologia Institucional da Universidade Federal do Espírito Santo (Ufes), Espírito Santo, Brasil. Doutora em Educação Brasileira pela Universidade Federal do Rio de Janeiro (UFRJ), com pós-doutorado em Saúde Pública pela Escola de Saúde Pública Sergio Arouca, da Fundação Oswaldo Cruz (Ensp/Fiocruz). < betebarros@uol.com.br>

4 Relato da professora Beatriz em entrevista ao pesquisador. Com objetivo de garantir o anonimato da docente que participou da pesquisa, atribuímos-lhe Beatriz como pseudônimo.

5 Por meio da autoconfrontação é possível "reencontrar todas as normas que compõem a atividade" (Schwartz, 2006, p. 459). Dessa forma, confrontam-se opiniões, atitudes, textos, situações sociais. É a ideia de problematização que articula a atividade de confrontar, que é indissociável a um trabalho com valores. "Confrontar confunde-se com a atividade de agir no mundo e faz parte das funções de organização do pensamento e da linguagem que orientam o desenvolvimento humano" (Vieira, 2004, p. 214).

6 Yves Clot é o principal autor da abordagem do trabalho intitulada "clínica da atividade". Nesta, a compreensão da relação entre trabalho e subjetividade não tem como foco a luta contra o sofrimento, mas a atividade de trabalho como fonte permanente de criação de novas formas de viver. Embora não trabalhe com o pressuposto do "corpo-si" defendido pela ergologia, a clínica da atividade, sob a ótica de Clot, amplia e complexifica a análise da atividade sob o prisma do coletivo, na medida em que, para esse autor, a atividade de trabalho refere-se a experiências e memórias coletivas que conformam um gênero profissional renovado por uma permanente estilização. A referência a um gênero profissional forte permite, segundo a clínica da atividade, o uso da experiência para a renovação desse mesmo gênero. Assim, afirmando as diferenças e proximidades metodológicas e conceituais entre a análise ergológica e a análise por meio da clínica da atividade, convocamos Clot à análise da atividade docente sempre que as composições com os dados sejam pertinentes. Além disso, a démarche ergológica, ao afirmar a produção de conceitos rigorosos e ressingularizações parciais no trabalho, admite a análise pluridisciplinar da atividade. Nesse sentido, Schwartz (2000, p. 7) dirá que: “O métier de ergologista não é um métier novo, fundado sobre um corpo disciplinar específico. É um modo de um ergonomista, um filósofo, um lingüista, um tecnólogo, um jurista, um dirigente, um engenheiro, um 
militante, exercer seu métier em conformidade com o que podemos dizer, hoje, da atividade humana".

7 Para Schwartz, competência é compreendida como "competência industriosa", resultado de uma combinatória problemática de diversos ingredientes que não podem ser avaliados por critérios universais. Assim, o desenvolvimento de competências está diretamente relacionado ao que se produz como valor. O autor afirma que, por meio do "corpo$\mathrm{si}^{\prime \prime}$, da linguagem, dos valores - entre o uso industrioso de si e outros momentos e dimensões da vida -, "múltiplas circulações em todos os sentidos cristalizam um núcleo comum e vago de 'competências para viver' e das polaridades específicas, segundo as características concretas em que cada indivíduo há de pô-lo em prática" (Schwartz, 1998, p. 5).

8 França, embasado na perspectiva ergológica de Schwartz, aponta duas principais características do sujeito industrioso, quais sejam: “Da célula ao meio, o sujeito 'industrioso' se constrói (ou se destrói) nesse debate de normas que está além de um diálogo situado entre uma prescrição formalizada e a atividade que se efetua, e, por meio da e na atividade, o sujeito não apenas negocia ou reage ao meio (à situação) de trabalho, mas trata daquilo que é para ele desejável e, portanto, relacionado ao conjunto de valores de sua sociedade" (França, 2004, p. 124).

9 De acordo com Schwartz (2004a, 2004b), considerar o trabalho como um projeto de produção "de mundos" implica afirmar que o trabalho nunca será pura execução devido à natureza infiel do meio. Ou seja, somente as prescrições e os conceitos não conseguem explicar nem prever fielmente como a atividade irá se desdobrar. Se o meio é sempre infiel, "todos os tipos de infidelidades se combinam, se acumulam, se reforçam uma na outra, no conjunto de um ambiente de trabalho que é também um ambiente técnico, um ambiente humano, um ambiente cultural" (Schwartz, 2007b, p. 2).

$10 \mathrm{O}$ sofrimento que paralisa e a dor estão relacionados aos sentimentos de indignidade, inutilidade e desqualificação experimentados pelos trabalhadores ao realizarem uma prescrição aquém de sua capacidade inventiva (Barros e Barros de Barros, 2007).

$11 \mathrm{O}$ prazer aqui entendido como "aquele no qual cabe ao trabalhador parte importante de sua construção" (Barros e Barros de Barros, 2007, p. 66).

\section{Referências}

BARROS DE BARROS, Maria Elizabeth; HECKERT, Ana Lúcia Coelho. As movimentações por escola e saúde: o conceito de atividade como operador de análise. In: REUNIÃO ANUAL DA ASSOCIAÇÃO NACIONAL DE PÓS-GRADUAÇÃO E PESQUISA EM EDUCAÇÃO, 29., 2006, Caxambu. Anais... Caxambu: Anped, 2006.
BARROS, Regina Benevides de; BARROS DE BARROS, Maria Elizabeth. Da dor ao prazer no trabalho. In: SANTOS-FILHO, Serafim Barbosa; BARROS DE BARROS, Maria Elizabeth (Orgs.). Trabalhador da saúde, muito prazer! Protagonismo dos trabalhadores na gestão do trabalho em saúde. Ijuí: Editora Unijuí, 2007. p. 61-71. 
BRACHT, Valter et al. Educação física escolar: entre práticas inovadoras e o desinvestimento pedagógico. Vitória: Universidade Federal do Espírito Santo, 2006. Projeto de pesquisa/CNPq.

BRITO, Jussara; ATHAYDE, Milton; NEVES, Mary Yale (Orgs.). Saúde e trabalho na escola. Rio de Janeiro: Cesteh/Ensp/Fiocruz, 1998.

CAMPOS, Gastão Wagner. Um método para análise e co-gestão de coletivos: a constituição do sujeito, a produção de valor de uso e a democracia institucional: o método da roda. São Paulo: Hucitec, 2000.

CANGUILHEM, Georges. O normal e o patológico. 3. ed. Rio de Janeiro: Forense, Universitária, 1990.

CLOT, Yves. A função psicológica do trabalho. Petrópolis: Vozes, 2006.

Clínica do trabalho e clínica da atividade. In: BENDASSOLLI, Pedro F.; SOBOL, Lis Andrea P. (Orgs.). Clinicas do trabalho: novas perspectivas para compreensão do trabalho na atualidade. São Paulo: Atlas, 2010. p.71-83.

CODO, Wanderley (Coord.). Educação: carinho e trabalho. Petrópolis: Vozes, 1999.

DURRIVE, Louis; SCHWARTZ, Yves. Glossário da ergologia. Laboreal, 2008, v. 4, n. 1, p. 23-28, 2008. Disponível em: <http://laboreal.up.pt/media/artigos/166/ glossario_v4n1_pt.pdf $>$.

FENSTERSEIFER, Paulo Evaldo et al. Educação física e cultura escolar: entre práticas inovadoras e o abandono do trabalho docente. Ijuí: Universidade Regional do Noroeste do Rio Grande do Sul, 2006. Projeto de pesquisa/CNPq.

FRANÇA, Maristela. No princípio dialógico da linguagem, o reencontro do homo loquens com ser humano industrioso. In: FIGUEIREDO, Marcelo et al. (Orgs.). Labirintos do trabalho: interrogações e olhares sobre o trabalho vivo. Rio de Janeiro: DP\&A, 2004. p. 115-131.

HUBERMAM, Michael. O ciclo de vida profissional dos professores. In: NÓVOA, Antonio (Org.). Vidas de professores. 2. ed. Porto: Porto Editora, 1999. p. 31-61.

NOUROUDINE, Abdallah. Risco e atividades humanas: acerca da possível positividade aí presente. In: FIGUEIREDO, Marcelo et al. (Orgs.). Labirintos do trabalho: interrogações e olhares sobre o trabalho vivo. Rio de Janeiro: DP\&A, 2004. p. 37-62.

PERÉZ GOMÉZ, Angel. La cultura escolar en la sociedade neoliberal. Madrid: Morata, 1998.

SANTINI, Joarez; MOLINA NETO, Vicente. Síndrome do esgotamento profissional em professores de Educação Física. Revista da Escola de Educação Física Esporte, São Paulo, v. 19, n. 3, p. 209-222, jul./set. 2005.

SCHWARTZ, Yves. Os ingredientes da competência: um exercício necessário para uma questão insolúvel. Revista Educação \& Sociedade, Campinas, v. 19, n. 65, dez. 1998.

Comunidade científica ampliada de pesquisa e o regime de produção de saberes. Tradução de Eloísa Santos e Daisy Cunha. Marseille: Cateis, 2000.

Disciplina epistêmica disciplina ergológica: paideia e politeia. Pró-Posições, Campinas, v. 13, n.1, p. 126-149, jan./abr. 2002a.

A abordagem do trabalho reconfigura nossa relação com os saberes acadêmicos: antecipações do trabalho. In: SOUZAE-SILVA, Maria Cecília P.; FAITA, Daniel (Orgs.). Linguagem e trabalho: construção de objetos de análise no Brasil e na França. São Paulo: Cortez, 2002b. p. 109-137.

Circulações, dramáticas, eficácias da atividade industriosa. Trabalho, Educação e Saúde, Rio de Janeiro, v. 2, n. 1, p. 33-55, 2004a. 
. Ergonomia, filosofia e exterritorialidade. In: FAITA, Daniel (Org.). A ergonomia em busca de seus princípios: debates epistemológicos. São Paulo: Edgar Blücher, 2004b. p. 141-181.

Trabalho e saúde: construindo outros modos de gestão. Trabalho apresentado no III Congresso Brasileiro de Ciências Sociais e Humanas em Saúde da Abrasco. Florianópolis, 13 jul. 2005.

Entrevista. Trabalho, Educação e Saúde, Rio de Janeiro, v. 4, n. 2, p. 457-465, 2006.

O trabalho se modifica. In: SCHWARTZ, Yves; DURRIVE, Louis (Orgs.). Trabalho e ergologia: conversas sobre atividade humana. Tradução de Jussara Brito et al. Niterói: EdUFF, 2007a. p. 23-47.

Trabalho e uso de si. In: SCHWARTZ, Yves; DURRIVE, Louis (Orgs.). Trabalho e ergologia: conversas sobre atividade humana. Tradução de Jussara Brito et al. Niterói: EdUFF, 2007b. p. 190-206.
Manifesto por um ergoengajamento. In: BENDASSOLLI, Pedro F.; SOBOL, Lis Andrea P. (Orgs.). Clínicas do trabalho: novas perspectivas para compreensão do trabalho na atualidade. São Paulo: Atlas, 2010. p. 132-166.

VIERA, Marcos Antônio. Autoconfrontação e análise da atividade. In: FIGUEIREDO, Marcelo et al. (Orgs.). Labirintos do trabalho: interrogações e olhares sobre o trabalho vivo. Rio de Janeiro: DP\&A, 2004. p. 214-235.

WITTIZORECKI, Elisandro Schultz; MOLINA NETO, Vicente. O trabalho docente dos professores de EF na rede municipal de ensino de Porto Alegre. Revista da Escola de Educação Física, Porto Alegre, v. 11, n. 1, p. 4770, jan./abr. 2005.

ZAGURY, Tânia. O professor refém. Rio de Janeiro: Record, 2006.

Recebido em 03/02/2011

Aprovado em 17/02/2011 